\title{
Improvement and Application of Logistic Growth Model
}

\author{
Lan Xiao", Yanqiu Chen
}

College of Applied Mathematics, Chengdu University of Information Technology Chengdu, Sichuan 610225, P. R. China

DOI: $10.36347 /$ sipms.2020.v07i09.002

| Received: 07.09.2020 | Accepted: 15.09.2020 | Published: 19.09.2020

*Corresponding author: Lan Xiao

Abstract

Review Article

Logistic growth model, as an important mathematical model to describe population or population changes, is now widely used in many fields. Researchers found that the problems involved cover many disciplines such as mathematics, physics, medicine, and biology. Therefore, the Logistic growth model has a strong application background and practical significance. This paper improves the logistic growth model that introduces harvest items, and applies the improved model to population forecasting. And with the help of mathematical software and the principle of least squares method to estimate the parameters of the improved model, the curve fitting comparison verifies that the improved model can achieve better results.

Keywords: Logistic growth model, Improvement, mathematics, physics, medicine.

Copyright @ 2020: This is an open-access article distributed under the terms of the Creative Commons Attribution license which permits unrestricted use, distribution, and reproduction in any medium for non-commercial use (NonCommercial, or CC-BY-NC) provided the original author and source are credited.

\section{INTRODUCTION}

\section{Logistic Model Background and Research Status}

The Logistic model was proposed by the Dutch mathematical biologist verhulst [1] in 1838. It is a commonly used model in biology. It describes a population growth law. The population initially grows in an accelerated manner. When a threshold is reached, the growth rate will decrease, and finally the growth rate will drop to zero and stop growing. At the same time, the Logistic growth model is often used to confirm the interaction (such as complementarity, competition) between populations. In actual research, there are continuous and discrete logistic models. In order to improve the accuracy and practicability of the Logistic growth model in predicting population numbers, many scholars have improved the Logistic growth model based on actual needs and promoted it to be rewarding The form of the function item.

In the literature [2], Laham et al., improved the Logistic model and used the model to formulate a fish capture plan, that is, when fishing can achieve the maximum profit without affecting the next stage of fish growth. So the harvest function is introduced, and the classic Logistic model.

$$
\frac{d x(t)}{d t}=r x(t)\left(1-\frac{x(t)}{C}\right), r>0, C>0,
$$

Amended to

$$
\frac{d x(t)}{d t}=r x(t)\left(1-\frac{x(t)}{C}\right)-H(t), r>0, C>0,
$$

Where $x(t)$ represents the number of the population at time $t, r$ represents the inherent growth rate of the population (that is, the birth rate minus the death rate), $C$ represents the environmental carrying capacity, and $H(t)$ is the harvest function.
In 2016, Alfred [3] studied the capture strategy of wrasse farming and discussed three types of harvest growth models: 
(1) Constant harvest growth model $\frac{d x(t)}{d t}=r x(t)\left(1-\frac{x(t)}{C}\right)-h$

(2) Proportional harvest growth model $\frac{d x(t)}{d t}=r x(t)\left(1-\frac{x(t)}{C}\right)-h x(t)$

(3) Cycle harvest growth model $\frac{d x(t)}{d t}=r x(t)\left(1-\frac{x(t)}{C}\right)-h(1+\sin 2 \pi t)$

The model indicates that a certain amount of wrasse is caught in a given time interval, and the optimal catch to protect wrasse from extinction is estimated, which provides an effective basis for formulating fishing strategies to maximize the benefits.

$$
\left\{\begin{array}{l}
\frac{d x(t)}{d t}=r(t) x(t)\left(1-\frac{x(t)}{C}\right)-H(t, x(t)) \\
x(0)=x_{0} .
\end{array}\right.
$$

This article also considers three types of harvest functions

(1) When the $H(t, x(t))$ harvest function is a function related to time $t$, in the population growth process, we assume that there is a certain linear relationship
On this basis, in order to better reflect the changing laws and trends of populations in complex environments. In 2020, the classic population model is improved in the literature [4], and the growth rate $r$ is expressed as a function $r(t)$ with respect to time $t$, so combined with previous research work, the following Logistic population growth model is established

$$
\left\{\begin{array}{l}
\frac{d x(t)}{d t}=r(t) x(t)\left(1-\frac{x(t)}{C}\right)-k r(t), \\
x(0)=x_{0} .
\end{array}\right.
$$

between the harvest function $H(t, x(t))$ and the growth rate $r(t)$, that is, there is a constant $k$ that makes $H(t, x(t))-k r(t)$, and the model becomes

(2) When the harvest function $H(t, x(t))$ is proportional to the population size $x(t)$, that is $H(t, x(t))=k r(t) x(t)$, the model can be expressed in the following form

$$
\left\{\begin{array}{l}
\frac{d x(t)}{d t}=r(t) x(t)\left(1-\frac{x(t)}{C}\right)-k r(t) x(t), \\
x(0)=x_{0} .
\end{array}\right.
$$

(3) When $H(t, x(t))=k r(t) x^{2}(t)$, the following model can be obtained

$$
\left\{\begin{aligned}
\frac{d x(t)}{d t} & =r(t) x(t)\left(1-\frac{x(t)}{C}\right)-k r(t) x^{2}(t), \\
x(0) & =x_{0} .
\end{aligned}\right.
$$


This article mainly solves the first form of model, and uses the solved result to predict the future population of China.

\section{MODEL SOLUTION}

Considering that the logistic growth model is used for population prediction, the harvest function can be expressed as the mortality rate of the population. From a practical point of view, the death rate of the population is related to the population number $x(t)$ and the growth rate $r(t)$. Therefore, this article mainly

$$
\left\{\begin{array}{l}
\frac{d x(t)}{d t}=r(t) x(t)\left(1-\frac{x(t)}{C}\right)-k r(t) x(t), \\
x(0)=x_{0} .
\end{array}\right.
$$

solves the second form of the model on the basis of the literature [4] and applies it to the population prediction. The predicted value is compared with the actual the values are curve-fitted.

Regarding the solution of the model in the second case, we consider that when the first case is established, when the harvest function $H(t, x(t))$ is proportional to the population size $x(t)$, the model is expressed in the following form:

(2-1) The process of solving equation is as follows: separate variables

$$
\left\{\begin{array}{l}
\frac{d x(t)}{d t}=r(t)\left[x(t)\left(1-\frac{x(t)}{C}\right)-k x(t)\right], \\
x(0)=x_{0} .
\end{array}\right.
$$

That is

$$
\begin{aligned}
& \frac{d x(t)}{x(t)\left[1-k-\frac{x(t)}{C}\right]}=r(t) d t, \\
& \frac{C d x}{x[C-k C-x]}=r(t) d t, \\
& \frac{1}{1-k}\left(\frac{1}{x}+\frac{1}{C-k C-x}\right) d x=r(t) d t,(\text { Integrate both sides simultaneously) } \\
& \frac{1}{1-k}\left[\int_{x_{0}}^{x} \frac{1}{s} d s-\int_{x_{0}}^{x} \frac{1}{C-k C-s} d(C-k C-s)\right] d x=\int_{0}^{t} r(t) d t, \\
& \ln x-\ln x_{0}-\ln (C-k C-x)+\ln \left(C-k C-x_{0}\right)=(1-k) \int_{0}^{t} r(t) d t, \\
& \ln \frac{x\left(C-k C-x_{0}\right)}{x_{0}(C-k C-x)}=(1-k) \int_{0}^{t} r(t) d t, \\
& \frac{x\left(C-k C-x_{0}\right)}{x_{0}(C-k C-x)}=e^{(1-k) \int_{0}^{t} r(t) d t},
\end{aligned}
$$

The solution is

$$
x(t)=\frac{x_{0}(C-k C)}{x_{0}+\left(C-k C-x_{0}\right) e^{(k-1) \int_{0}^{t} r(t) d t}} \approx \frac{x_{0}(C-k C)}{x_{0}+\left(C-k C-x_{0}\right) e^{(k-1) r t}}
$$


(Since the change of $r$ with time is small, it is approximated as a constant here) $C, k, r$ is the parameters in the model.

\section{Model Parameter Estimation and Curve Fitting}

For the improved Logistic model, this paper uses the principle of least squares method [5] to estimate the three unknown $x(t)=\frac{x_{0}(C-k C)}{x_{0}+\left(C-k C-x_{0}\right) e^{(k-1) \int_{0}^{t} r(t) d t}}$ parameters in $C, k, r$, then it is necessary to solve the minimum residual square sum between the observed value and the actual value

$M=\min \sum_{t=1}^{n} u_{t}^{2}=\min \sum_{t=1}^{n}\left(x_{t}-x(t)\right)^{2}$,

Where $x_{t}$ represents the actual population at time $t$, and $x(t)$ represents the predicted population at time $t$.

Then use the formula (3-1) to derivate $C, k, r$ to be equal to zero, and establish a system of equations

$$
\left\{\begin{array}{l}
\frac{\partial M}{\partial C}=0, \\
\frac{\partial M}{\partial k}=0, \\
\frac{\partial M}{\partial r}=0 .
\end{array}\right.
$$

In order to solve the estimated value of $C, k$, $r$ the approximate values of the three parameters can be obtained as follows: $C \approx 18.6337, k \approx 0.0694, r \approx 0.0516$ (The result is to four decimal places)

Substituting three parameters into $x(t)$, we get $x(t) \approx \frac{82.8870}{5.5196+11.8209 \mathrm{e}^{(-0.0480 \mathrm{t})}}$.

According to statistics from the official website of the National Bureau of Statistics of China [6], the population data of China from 1950 to 2019 in 69 years is shown in Table-1.

\begin{tabular}{|c|c|c|c|c|c|c|c|c|}
\hline Time $\mathbf{t}$ & Year & $\begin{array}{l}\text { Actual total } \\
\text { population }(100 \\
\text { million) }\end{array}$ & Time $t$ & Year & $\begin{array}{l}\text { Actual total } \\
\text { population }(\mathbf{1 0 0} \\
\text { million) }\end{array}$ & Time $\mathbf{t}$ & Year & $\begin{array}{l}\text { Actual total } \\
\text { population }(100 \\
\text { million) }\end{array}$ \\
\hline $\mathrm{t}=0$ & 1950 & 5.5196 & $\mathrm{t}=24$ & 1974 & 9.0409 & $\mathrm{t}=48$ & 1998 & 12.4761 \\
\hline $\mathrm{t}=1$ & 1951 & 5.6300 & $\mathrm{t}=25$ & 1975 & 9.1970 & $\mathrm{t}=49$ & 1999 & 12.5786 \\
\hline $\mathrm{t}=2$ & 1952 & 5.7482 & $\mathrm{t}=26$ & 1976 & 9.3267 & $\mathrm{t}=50$ & 2000 & 12.6743 \\
\hline $\mathrm{t}=3$ & 1953 & 5.8796 & $\mathrm{t}=27$ & 1977 & 9.4774 & $\mathrm{t}=51$ & 2001 & 12.7627 \\
\hline$t=4$ & 1954 & 6.0266 & $\mathrm{t}=28$ & 1978 & 9.6259 & $\mathrm{t}=52$ & 2002 & 12.8453 \\
\hline $\mathrm{t}=5$ & 1955 & 6.1465 & $\mathrm{t}=29$ & 1979 & 9.7542 & $\mathrm{t}=53$ & 2003 & 12.9227 \\
\hline $\mathrm{t}=6$ & 1956 & 6.2780 & $\mathrm{t}=30$ & 1980 & 9.8705 & $\mathrm{t}=54$ & 2004 & 12.9988 \\
\hline $\mathrm{t}=7$ & 1957 & 6.4238 & $\mathrm{t}=31$ & 1981 & 10.0072 & $\mathrm{t}=55$ & 2005 & 13.0756 \\
\hline $\mathrm{t}=8$ & 1958 & 6.5346 & $\mathrm{t}=32$ & 1982 & 10.1654 & $\mathrm{t}=56$ & 2006 & 13.1448 \\
\hline $\mathrm{t}=9$ & 1959 & 6.6012 & $\mathrm{t}=33$ & 1983 & 10.3008 & $\mathrm{t}=57$ & 2007 & 13.2129 \\
\hline $\mathrm{t}=10$ & 1960 & 6.6207 & $\mathrm{t}=34$ & 1984 & 10.4357 & $\mathrm{t}=58$ & 2008 & 13.2802 \\
\hline $\mathrm{t}=11$ & 1961 & 6.6457 & $\mathrm{t}=35$ & 1985 & 10.5851 & $\mathrm{t}=59$ & 2009 & 13.3450 \\
\hline$t=12$ & 1962 & 6.7295 & $\mathrm{t}=36$ & 1986 & 10.7507 & $\mathrm{t}=60$ & 2010 & 13.4091 \\
\hline $\mathrm{t}=13$ & 1963 & 6.9172 & $\mathrm{t}=37$ & 1987 & 10.9300 & $\mathrm{t}=61$ & 2011 & 13.4735 \\
\hline$t=14$ & 1964 & 7.0499 & $\mathrm{t}=38$ & 1988 & 11.1026 & $\mathrm{t}=62$ & 2012 & 13.5404 \\
\hline$t=15$ & 1965 & 7.2538 & $t=39$ & 1989 & 11.2704 & $\mathrm{t}=63$ & 2013 & 13.6072 \\
\hline$t=16$ & 1966 & 7.4206 & $\mathrm{t}=40$ & 1990 & 11.4333 & $\mathrm{t}=64$ & 2014 & 13.6782 \\
\hline $\mathrm{t}=17$ & 1967 & 7.6032 & $t=41$ & 1991 & 11.5823 & $\mathrm{t}=65$ & 2015 & 13.7462 \\
\hline $\mathrm{t}=18$ & 1968 & 7.8198 & $\mathrm{t}=42$ & 1992 & 11.7171 & $\mathrm{t}=66$ & 2016 & 13.8271 \\
\hline$t=19$ & 1969 & 8.0335 & $t=43$ & 1993 & 11.8517 & $\mathrm{t}=67$ & 2017 & 13.9008 \\
\hline$t=20$ & 1970 & 8.2542 & $\mathrm{t}=44$ & 1994 & 11.9850 & $\mathrm{t}=68$ & 2018 & 13.9538 \\
\hline $\mathrm{t}=21$ & 1971 & 8.4779 & $t=45$ & 1995 & 12.1121 & $\mathrm{t}=69$ & 2019 & 13.9538 \\
\hline$t=22$ & 1972 & 8.6727 & $t=46$ & 1996 & 12.2389 & & & \\
\hline $\mathrm{t}=23$ & 1973 & 8.8761 & $\mathrm{t}=47$ & 1997 & 12.3626 & & & \\
\hline
\end{tabular}

Table-1: Chinese population data 
In order to test the accuracy of the improved Logistic model, the actual data of China's population from 1950 to 2019 in Table-1 were fitted with the predicted values. The results are shown in Figure-1.

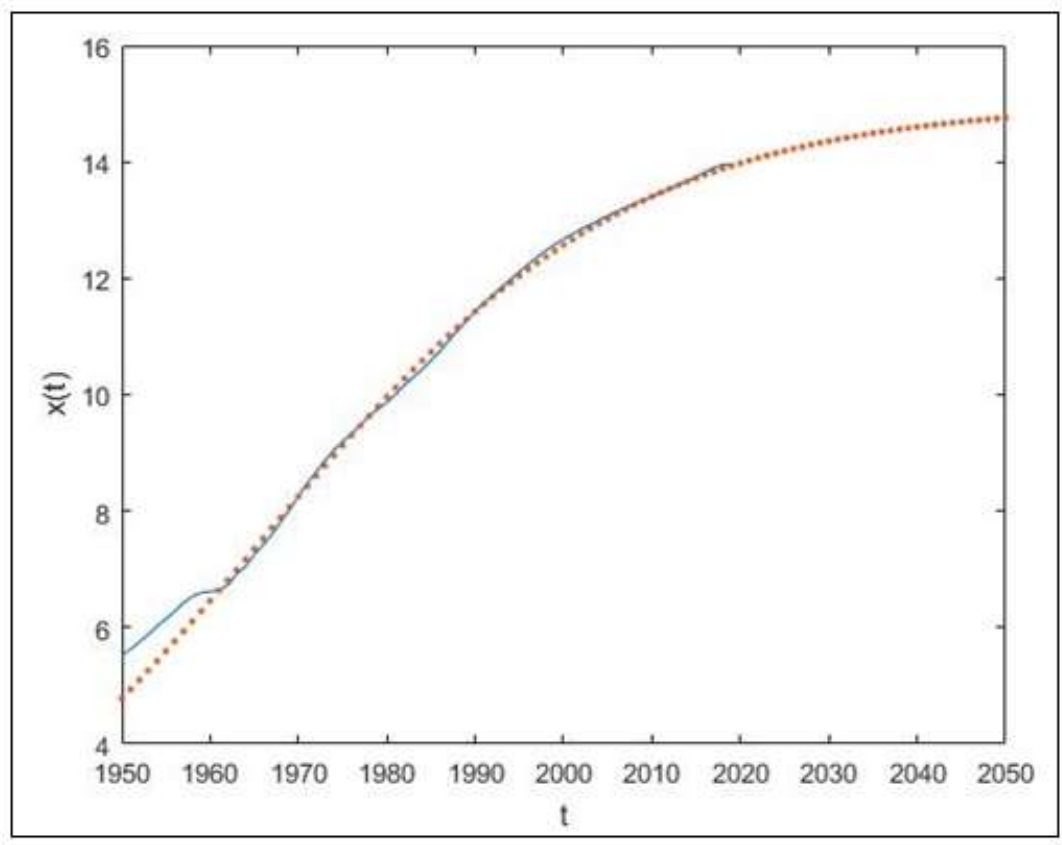

Fig-1

Note: The abscissa 1 in the figure represents the year (unit: year), and the ordinate 2 represents the population (unit: 100 million)

\section{DISCUSSION}

This paper uses the improved Logistic growth model to estimate its parameters using the principle of least squares. The obtained predicted value is compared with the actual value. The degree of fit increases with the year, the higher the degree of fit, indicating that the improved logistic growth model can predict more accurately.

\section{MODEL PROMOTION}

The Logistic growth model was originally used for population growth, and in the epidemiological control of infectious diseases, there is a similar model used to limit the number of infected populations and the number of latent populations, so that these populations cannot spread to a larger number of people disease. At the end of 2019, there was a sudden epidemic situation. Many scholars have conducted research on the prediction of the new coronavirus. Among them, a large number of scholars used the Logistic model to predict the epidemic trend of COVID-19. If the Logistic growth model improves the model based on factors that consider the actual forecast needs, the improved model can be extended to the application of multiple disciplines, and it can better reflect its practical application significance.

\section{REFERENCES}

1. Verhulst, P. (1838). Notice Sur La Loi Que La Population Suit Dans Son Accroissement. Correspondance Mathématique et Physique, 10:113-121.

2. Laham, M. F., Krishnarajah, I. S., \& Shariff, J. M. (2012). Fish Harvesting Management Strategies Using Logistic Growth Model. Sains Malaysiana, 41(2):171-177.

3. Alfred. (2016). Fish Harvesting Models and Their Applications in a reservoir in Sanrada Albania, 3(7):5279-5282.

4. Chen, X., \& Xiao, L. (2020). Improvement of Logistic Model and Chinese Population Forecast. Journal of Chengdu University of Information Technology.

5. Zheng, X., Luo, Q., Yao, L., \& Song, J. (2015). Parameter estimation and program realization of population retarded growth model. Mathematics Learning and Research, 1:132.

6. http://www.stats.gov.cn/tjsj/ndsj/. 